\title{
Der Mieterichun
}

Sammlung ber Beroronumgen

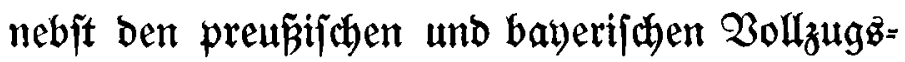
vorifariften

\section{Ërläutert}

von

\section{Dr. Qubwig $\mathfrak{Q e b} \mathfrak{m a n n}$}

Silfżreferent am Staotmagiftrat Regenz̋burg.

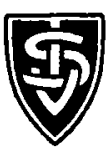

1919

Mündxen, Berlin und Reipzig

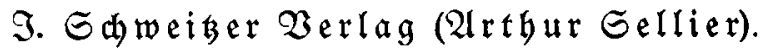




\title{
Leipziger Zeitschrift
}

\section{für Deutsches Recht}

\author{
Unter Leitung von Dr. F. von Mutner, H. Staatumitisler D \\ herausgegeben von \\ Dr. A. Düringer Dr. L. Ebermayer Dr. M. Hechenburz
}

$\begin{array}{llll}\text { Dr. E. Jaeger } & \text { H. Könige } & \text { E. Meyn }\end{array}$

Die "Reipziger Beitf(hrift" miomet fid

bem gejamten Ientiden Redt einidl. bes Strajredjt:

Fhre befonderen Borzüge find:

Eofortige prattifige Berwendbarteit Des Jubalts

Ausidlub jeber Gintag 8 =iteratur

Gorgfältige ueberprü|ung der Beiträge durd bie Medattion Heberaus zablreide Gutideionngen bes $\Re 6$., bejoriders aud Det OQB. nnd 28 .

Gewifienhafte Wuswahl und Searbeitung ber Cutfdeidungen burd Mitnlieber ber betr. Geridhtshöft unter bejouberer Beritdfidtipung Der Anwalts: :sediefuifie

Gropes explénen bei ben Gerimten

14 tägige Erideinen und baber alsbaldige Berihterftattung

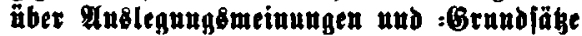

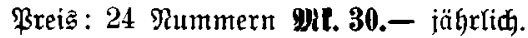

Tud die älteren 3ahrgänge der $\mathbb{8} 3$. haben hoten $\mathfrak{B e}=$ nuknungs = und Bibliothet3mert. Die siriegsjafhrgänge 1914-1918 empfeflen mir bejonders den 尺riegsteilnehmern.

Brobehefte foitenloz.

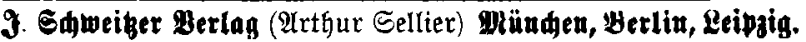




\section{Der Mieteridatu}

Sammlung Der Beroronungen

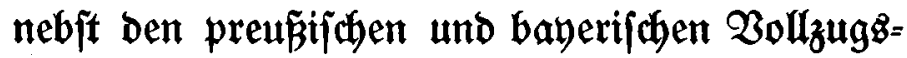
vorfariften

\section{Ěrtäutert \\ bon}

\section{Dr. Qubwig Qebmann}

Silfồreferent am Stabtmagiftrat Regenşburg.

1919

Mündjen, Bexlin unb Seipztg

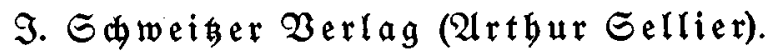


